\title{
Correction to: Recalibration and validation of the Swiss lichen bioindication methods for air quality assessment
}

\author{
Rolf Herzig ${ }^{1} \cdot$ Christian Schindler ${ }^{2,3} \cdot$ Martin Urech $^{4} \cdot$ Beat Rihm $^{5} \cdot$ Hanspeter Lötscher $^{6} \cdot$ Georg Thomann $^{6}$ \\ Published online: 22 June 2020 \\ (C) Springer-Verlag GmbH Germany, part of Springer Nature 2020
}

Correction to: Environmental Science and Pollution Research https://doi.org/10.1007/s11356-020-09001-x

The correct fig. 2 is presented in this paper.

The original article is corrected.

The online version of the original article can be found at https://doi.org/ 10.1007/s11356-020-09001-x

\footnotetext{
Rolf Herzig

rolf.herzig.agb@bluewin.ch
}

1 AGB, Arbeitsgemeinschaft für Bioindikation, Umweltbeobachtung und ökologische Planung, Quartiergasse 12, 3013 Bern, Switzerland

2 Swiss Tropical and Public Health Institute, Basel, Switzerland

3 University of Basel, Basel, Switzerland

4 puls, Umweltberatung, Bern, Switzerland

5 Meteotest AG, Bern, Switzerland

6 Amt für Natur und Umwelt, Chur, Switzerland 
Fig. 2 Correlations (R2adj) of new lichen-indices for primary pollutants, NH3 and AOT40f and of the traditional index IAP18 with logtransformed air pollutant and meteo variables for entire Switzerland. a The new primary pollutant lichen index (PP-LI) shows a high multivariable correlation (adj R2 $=0.86$ ) with primary pollutant variables $\ln (\mathrm{PM} 10), \ln (\mathrm{SO} 2), \ln (\mathrm{NO} 2)$ (left blue bar), followed by bivariate correlations with individual primary pollutant variables (other blue bars). The bivariate correlations with the other pollutant variables $(\ln (\mathrm{NH} 3)$ and $\ln ($ AOT40f), dark gray bars) and the logtransformed meteo variables (light gray bars) follow on the right side of the bar graphs. $b$ AOT40f

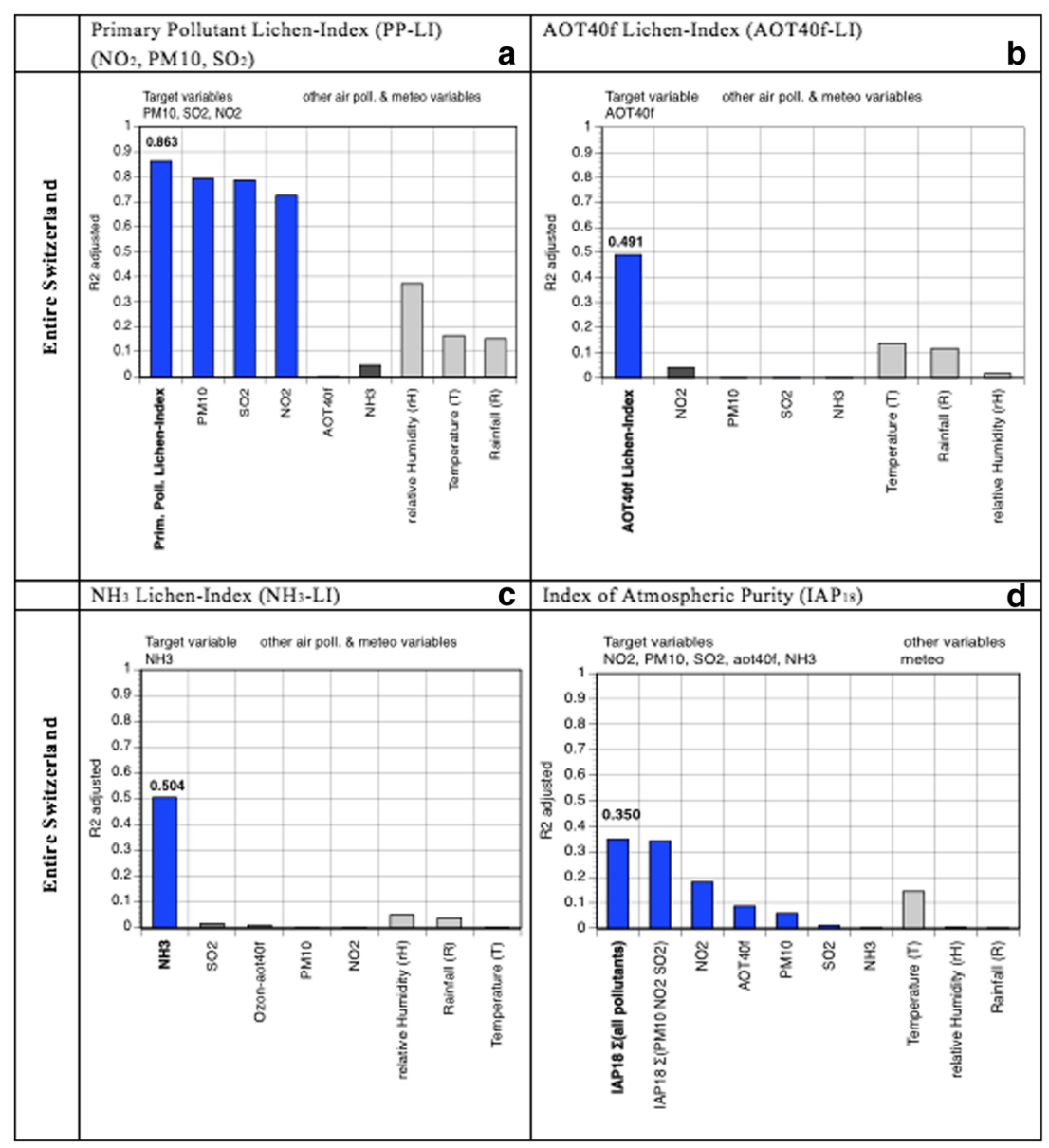

Publisher's note Springer Nature remains neutral with regard to jurisdictional claims in published maps and institutional affiliations. 